\title{
Towards a Collective-Values Framework of Ubuntu: Implications for Workplace Commitment
}

\author{
Thembisile Molose, Geoff Goldman, Peta Thomas
}

\begin{abstract}
A B S T R A C T
Objective: This research offers an extension of current research on commitment across cultures. It incorporates the concept of Ubuntu as an integrating model that can be paired up with other perspectives for directing employee workplace commitment.

Research Design \& Methods: A literature review entailing concepts related to crosscultures and their relationship to Ubuntu and commitment was considered. The review spanning 50 years covered online-databases of global and African research.

Findings: We argue here that the conceptualisation of Ubuntu is important in adapting currently accepted cultural frameworks as operationalised by individualism, collectivism and power distance dimensions for regional management application. Ubuntu collective values (compassion, survival, group solidarity, respect and dignity), which relate affirmatively with a sense of workplace collectivism, was identified as a unique element of cultural management philosophy for directing personal interactions, workplace commitment and performance management improvements.

Implications \& Recommendations: Ubuntu should be facilitated by managers as a motivational force that facilitates workplace commitment ensuring organisational team performance. The implications of Ubuntu in the context of extending existing theories of individualism-collectivism and power distance cannot be overstated.
\end{abstract}

Contribution \& Value Added: A model based on relationships between Ubuntu collective values and EWC, applicable with contextual managerial frameworks.

\section{Article type: conceptual research article}

Keywords: $\quad$ performance management; South Africa; workplace commitment JEL codes: J08; M14

Received: 26 April 2018 Revised: 20 August 2018 Accepted: 21 August 2018

\section{Suggested citation:}

Molose, T., Goldman, G.A., \& Thomas P. (2018). Towards a Collective-Values Framework of Ubuntu: Implications for Workplace Commitment. Entrepreneurial Business and Economics Review, 6(3), 193206. https://doi.org/10.15678/EBER.2018.060312 


\section{INTRODUCTION}

Over the last decade, research into organisational behaviour (OB) which encourages employee workplace commitment (EWC), organisational commitment (OC) and consequently organisational performance improvements, has gained attention (Dhar, 2015; Jaiswal \& Dhar, 2016). Studies identified that workplace diversity derived from a region's culture has a profound effect on organisational performance potentials (Mangaliso, 2001; Stinglhamber \& Vandenberghe, 2003; Meyer, Stanley, Jackson, McInnis, Maltin, \& Sheppard, 2012).

Tett and Meyer (1993) stated that regional culture is a determinant of EWC and OB, yet it is overlooked as to the influence it has on management practice. The subjugation of African regional cultural influences, such as Ubuntu, is unfortunately rooted in colonialisation, industrialisation and their resulting life changes for African people (Msengana, 2006, p. iv). This article addresses the southern African indigenous knowledge of Ubuntu. For the purposes of this article, Ubuntu is defined by Khoza (2005, p. 269) as 'an African value system that is characterized by caring, sharing, compassion, communocracy and related predispositions'.

We argue here that the conceptualisation of Ubuntu is important in adapting currently accepted cultural frameworks as operationalised by individualism, collectivism and power distance dimensions for regional management application (Mbigi \& Maree, 1995; Hofstede, 1980; House, Hanges, Javidan, Dorfman, \& Gupta, 2004). The specific aims are to:

- Review the influence of culture differences associated with power distance and individualism-collectivism on EWC (e.g. supervisor, work team or co-workers);

- Identify which attributes of employee commitment in Ubuntu community should be developed to enhance service quality behaviour and competitiveness;

- Draw up practical implications for management and workplace organisations with a theoretical model of Ubuntu collective values, and;

- Encourage an extension of current research on commitment and increase our global understanding of geographic cultural influences such as Ubuntu.

\section{LITERATURE REVIEW}

\section{The Development of Culture as an Influence in OB and OC}

OC was viewed by Becker (1960, p. 33) as a resultant of an employee's tendency to 'engage in consistent lines of activity'. Building from this definition, studies identified EWC from various perspectives (Table 1).

Affective OC research by Mowday et al. (1979) is considered by LaMastro, (1999) as one of the most important approaches to OC. The latter pertains to EWC as defined in a specific referent (e.g. occupation, profession, staff-supervisor, teams). This was an important development as it explained to some extent EWC behaviour. Rousseau (1989) then argued that employees do demonstrate high levels of OC not only to career, but also to the organisation. Honeycutt (1989) then highlighted that this can translate into a sense of organisational belonging and corporate identity amongst one's peers. EWC was subsequently defined in terms of referent effects in its nature and origin as stabilising employee psychological mindset which, when managed, can give rise to a particular positive behav- 
iour (Meyer \& Maltin, 2010, p. 324). Research has since encouraged a more people-centred approach to articulating factors that positively influence OC understanding of the culturally-driven importance individuals attached to group membership (Meyer, Morin, \& Vandenberghe, 2015; Li, Kim, \& Zhao; 2017). Stinglhamber and Vandenberghe (2003) examined successful employee-supervisor linkage characteristics, moving away from the traditional focus of the employer OC. Perceived supervisor support (PSS) in supervisor-employee linkages was found to relate to how supervisor's views and values could lead to improved EWC. Mastrangelo, Eddy and Lorenzet (2004) suggested that 'negative workplace experiences of a supervisor seen as untrustworthy and uncaring by employees, makes them less committed to the work and to the organization' (p. 442).

Table 1. Various conceptual perspectives of commitment

\begin{tabular}{|c|c|c|}
\hline Affective commitment & Continuance commitment & Normative commitment \\
\hline $\begin{array}{l}\text { 'A desire to stay with the organi- } \\
\text { sation associated with his/her } \\
\text { willingness to exert effort on be- } \\
\text { half of the organisation and } \\
\text { his/her trust in and acceptance } \\
\text { of the values and goals of that } \\
\text { organisation' (Mowday, Porter, } \\
\text { \& Steers, 1979, p. 226). }\end{array}$ & $\begin{array}{l}\text { Stebbins }(1970, \text { p. } 527) \text { de- } \\
\text { fines calculative or continu- } \\
\text { ance commitment as 'the } \\
\text { awareness of the impossibil- } \\
\text { ity of choosing a different so- } \\
\text { cial entity... because of the } \\
\text { immense penalties in making } \\
\text { the switch'. }\end{array}$ & $\begin{array}{l}\text { Wiener (1982, p. 471) defines it as } \\
\text { the 'totality of internalized nor- } \\
\text { mative pressures to act in a way } \\
\text { which meets organisational goals } \\
\text { and interests which suggest that } \\
\text { individuals exhibit behaviours } \\
\text { solely because 'they believe it is } \\
\text { the right and moral thing to do'. }\end{array}$ \\
\hline
\end{tabular}

Source: own elaboration based on literature.

Models of OC also began to identify numerous employee proxy variables, such as age, gender and number of years with the organisation, as having a role to play in OC (Meyer \& Allen, 1991; Meyer, Stanley, Herscovitch, \& Topolnytsky, 2002; Vveinhardt \& Andriukaitiene, 2017). Multidimensional OC models incorporating these components and its influence on OB have become widely accepted (Mathieu \& Zajac, 1990; Meyer, Stanley, Herscovitch, \& Topolnytsky, 2002; Gellatly, Meyer, \& Luchak, 2006). Various research now seek to understand EWC in terms of regional culture, perceived impact on leadership behaviours and its influence on OB as initiated by Hofstede (1980). Culture was defined by Hofstede (1980, p. 43) 'as the collective programming of the mind which distinguishes the members of one group of people from another'. The link of Ubuntu as a notion of collectivism within African cultures was espoused by Hofstede (1980) noting that in African culture the group has more importance than the individual so group success is more valued than individual success. Hofstede (1980) identified five cultural dimensions (individualismcollectivism, power distance, masculinity-feminism and uncertainty avoidance) as a common basis for measuring the influence of a regional culture in OC.

Dimensions from Hofstede's framework: individualism, collectivism and power distance, have particular relevance in this discussion and are now described as underpinning Ubuntu cultural principles:

1. Power distance: The extent to which less powerful members of a society accept and expect that power is distributed unequally (Hofstede, 1980, p. 52);

2. Individualism: The extent to which the identity of individuals in a society is based upon personal qualities (Hofstede, 1980, p. 52); 
3. Collectivism: The extent which the identity of individuals or group memberships is based upon the community or organisation (Hofstede, 1980, p. 52).

'The Global Leadership, Organisational and Behavioural Effectiveness (GLOBE)' study by House et al. (2004) advanced arguments that individualism-collectivism and power distance were culturally and universally applicable. This fundamentally implied that, to succeed in a global business context, managers need the flexibility to respond positively and effectively by integrating different cultures to employee supervision, practices and values that may be dramatically different from what they are accustomed to (House et al. 2004).

These authors highlighted that management practice in the sub-Saharan African context is known for embracing humanness and interdependency as embedded in Ubuntu characterised by upholding group norms of reciprocity and suppression of personal interest for the good of the group. House et al. (2004) acknowledged culturally-endorsed leadership noting it as a distinctive philosophical concept that sub-Saharan Africa organisational managers should focus on when elevating EWC. Indeed, considerable research in the $O B$ discipline has truly begun to review the influence of regions and associated cultures on management (Gellatly et al., 2006; Fischer \& Mansell, 2009; Meyer et al., 2012, 2015; Astakhova, 2016; Li, Kim, \& Zhao; 2017; Limpanitgul, Boonchoo, Kulviseachana, \& Photiyarach, 2017; Valickas et al., 2017). Ubuntu as a culture in management, centred in an African interpretation of humanness is now presented.

\section{Ubuntu as a Dimension of African Culture and Humanness}

As a culture, Ubuntu is attributed to the longings of African people for communal bonds that researchers aspire to explain. Christie, Lessem and Mbigi (1993) noted that Ubuntu in the community or workplace brings forth images of supportiveness, co-operation and solidarity. Ndaba (1994) and Battle (1996) proposed that the culture of Ubuntu reflects both an ontological and an epistemological stance in the African thought of Bantu-speaking people. In this context, the ideal upheld by Ubuntu is that it allows a person to grow and prosper in a relational setting by providing ongoing contact and interaction with others. These authors suggest that Ubuntu as a group culture does not however support oppressive communalism.

This is why Mangaliso (2001) argues that Ubuntu is a conventional wisdom that supports customs and practices that serve only the common good. Nussbaum (2003) added that Ubuntu cannot be considered synonymous with any existing paradigms applied in Western interpretations of individualism or collectivism, noting it expresses a unique African view of the world anchored in its very own person, culture and society which is difficult to define by current empirical Western contexts.

The defining of Ubuntu has not been restricted to academic writers. South African public figures like Archbishop Desmond Tutu and former South African president Nelson Mandela used Ubuntu characteristics in public speeches to encompass a perspective that a person with Ubuntu as a culture sees others as fellow human beings. Tutu (1995, p.15) described Ubuntu as the essence of practising a culture of being human and a gift that Africa gives to the world. A more practical example of Ubuntu was provided by Mandela during a television interview with South African journalist, Modise (2006). Mandela described Ubuntu with a story, 'A traveler through a country would stop at a village and he 
didn't have to ask for food or for water; once he stops, the people give him food and entertain him'. Mandela added that this was only one aspect of Ubuntu, as the concept can have various meanings as interpreted by each individual.

Mandela's sentiments with African traditions of hospitality are supported in academic treatise where Brotherton and Wood (2008) draw attention to African hosts who open his/her home to total strangers giving them a place to stay and a meal to eat although he/she knew nothing about them. This kind of hospitality exists as unlimited and is not guided by the parameters of laws and concepts (Westmoreland, 2008). From these famous orators to the academic writers, the denominators of Ubuntu seems to promote actions that are welcoming, concerned principally with sharing and sustaining human relations. It is argued here that Ubuntu is derived from efforts that explicate how peoples' actions interrelate to maintaining togetherness in a community.

As regards describing the meaning of African humanness in terms of individualism, collectivism and power distance, sub-Saharan connotations are described by phrases such as the Zulu, 'Umuntu-ngumu-ntu ngabantu', which means 'a person is a person through others' (Battle, 1996, p. 99). Mbigi (1997) and Metz (2007) support this suggesting that among South Africa Zulu and Xhosa people the notion that a person can only be a person through others is widely accepted. Many Zulu and Xhosa people also use terms like 'Sawubona' when they greet, which means, 'I see you (as human)' and 'Simunye' meaning 'we are one' as pre-proposed by Ubuntu.

This article posits then that Ubuntu characteristics are in management terms:

- Describing humanness-that may well be unique to an African management context and specifically Sub-Saharan contexts requiring the organisation to capture the essence of what it means to be 'we are one', resonating with employees in supporting their deeply held regional beliefs and cultural systems;

- Workplace commitment-ensuring burdens of the community of employees are shared so that no one is prejudiced;

- $O C$ through $O B$ as instigated by manager behaviour-which ensures the interest of the community of employees ahead of the interests of any individual.

\section{Ubuntu as a Management Philosophy}

As a management philosophy, Ubuntu has been gaining rapid prominence recognizing the role of humanness that focuses on selflessness and commitment of an individual to one's community. In the domain of management, the community is that of one's daily work colleagues or team. An important articulation of the characteristics of Ubuntu as culture can be found in Mbigi and Maree's (1995) conceptual framework of Ubuntu, known as the Collective-Fingers' theory. Here, five values of Ubuntu are postulated as integral to its expression - survival, compassion, spirit of solidarity, respect, and dignity. This theory is analogous to describing the principles of community and togetherness of Ubuntu culture as a human hand. Accordingly, a hand perfectly represents the Ubuntu concept as it requires the collective co-operation of all fingers and the thumb to function optimally (Mbingi \& Maree, 1995). These authors' draw on an African proverb in defining this model, noting that 'a thumb, although strong, cannot kill on its own', inferring it needs support from the rest of the hand.

Mbingi and Maree (1995) argue that this African proverb can be interpreted from 
a managerial viewpoint, in two ways: firstly, the five fingers represent individual persons who act together in a collective manner in order to achieve a certain goal reflected by commitment to the organisation. Secondly, fingers represent key values that are necessary when forming and maintaining a collective culture (Mbigi, 1997). Ubuntu therefore can be seen as one of the indigenous knowledge mechanisms capable of promoting synergy and the creation of a whole that is larger than the sum of the individual parts (Mangaliso, 2001). Other studies (Poovan, du Toit, \& Engelbrecht, 2006; Lutz, 2009) advocated that the five fingers can be compressed from five to four values combining respect and dignity as one. MacDonald et al. (2014) support this view suggesting that managers must lead their subordinates to build the solidarity and commitment required for strong workplace relationships, productive teamwork, and, strong loyalty to organisational goals.

Another trend distinguishable since the 1990s is the use of the term Ubuntu as the connection between a leadership style and management, increasingly becoming important as a factor in the realm of South African management and organisational re-imagination (Mangaliso, 2001; Nussbaum, 2003; Nyathi, 2008). A recent theory of Ubuntu proposed by Woermann and Engelbrecht (2017, p. 4), 'the relation-holder theory', contends that Ubuntu promotes collective decision making and in management terms they explain Ubuntu in reference to the aphorism 'a person is a person through others', suggesting that a manager is a successful manager because of his/her team.

We now propose a theoretical framework based on the four Ubuntu values (Figure 1) as concepts drawn from literature to guide managers in developing the leadership characteristics appropriate to supervising a collective team in a South African workplace.

Applying the collective-fingers theory to team management promotes what Tutu (2004) calls 'a family or an organization'. Tutu (2004) attributes Ubuntu to common understanding between the supervisor and work teams so that they help and care for each other as members of one family. Jackson (2004) remarks that Ubuntu's point of departure should be centred on the leader's actions (the thumb) as the driver of a cohesive force within the group promoting humanness and each team member's interpersonal role.

\section{The Power Distance Mechanism of Ubuntu in Workplace Commitment}

The power distance mechanism acting between employees and their supervisor under Ubuntu collective values, particularly that of compassion and of spirit of solidarity, and their associated influence on EWC and behaviour - are evident in very few studies. This suggests that empirical research examining Ubuntu in influencing EWC and work behaviour outcomes is still relatively unexplored in contemporary management literature. Ubuntu collective values and their influence on work behaviour, identified in the South African context, appear to be centred on managers who do not have an understanding of the implications for leading teams of various cultures and languages (Nicolaides, 2010). Mangaliso's (2001) research based on reviewing conceptions and reflections about experiences of Ubuntu found in South African private and state-owned enterprises stated that while Ubuntu might be difficult to prove by setting indicators, greater commitment to the goals of the organisation translating into measuring effectiveness and efficiency is indeed possible when Ubuntu is embraced. He highlights that this occurs because applying Ubuntu principles in leadership reinforce understanding among all employees, which results in group solidarity, teamwork and, collective pride in achieving organisational goals. 


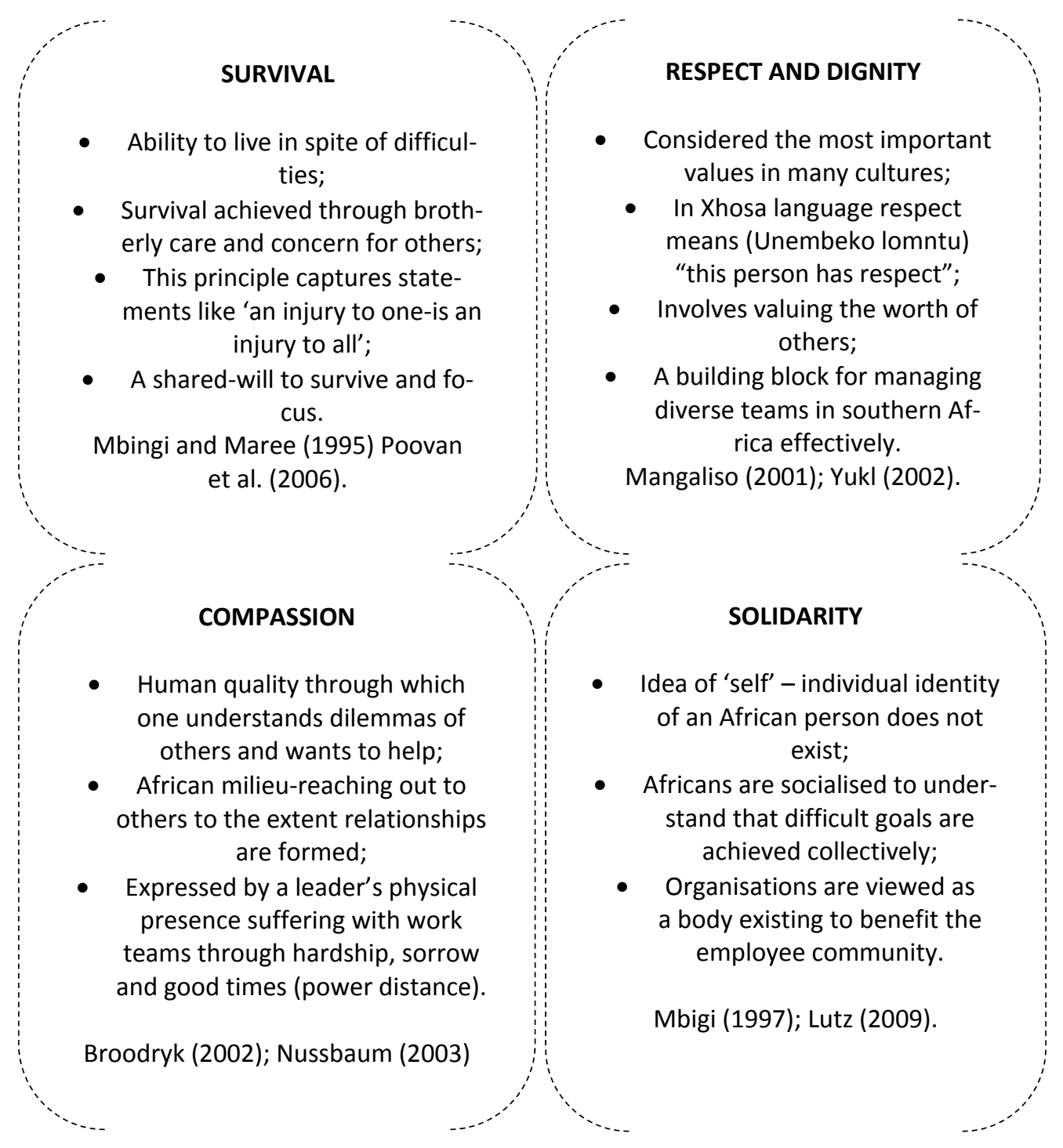

Figure 1. Collective-values of Ubuntu framework Source: Molose (2017).

Mangaliso (2001) argues that helpfulness towards others in a work team creates a climate of collegiality based on sharing and caring because of an Ubuntu intrinsic understanding that all humans are interconnected. Poovan et al. (2006) provided empirical support, noting that Ubuntu allows for workplace personal understanding and caring, which enables team members to see themselves as belonging to a community even at work, and consequently they are more willing and committed to help each other and the organisation. 
Browning (2006) found during interviews with frontline-employees of South African retail car companies and hospitality organisations that South African employees attach importance to building relationships, personal interaction and mutual respect as emphasized in Ubuntu culture. However, additional findings showed that managers failed to provide employees with the physical and emotional support needed when dealing with difficult guests. Browning (2006) concluded that managers who lead in a way that contradicts the expectations of their employees do not realize the positive influence they could have had through Ubuntu, which can influence employees positively when interacting with customers. The link between Ubuntu collective-values and EWC is evident in Batho Pele principles (people first) which are deliberately drawn on an Ubuntu model in South African government policy of 'serving people first' (Mangaliso, 2001; Yukl, 2002). Batho Pele is a government espoused, nation-wide initiative requiring public servants to be service-orientated, and to commit to continuous service delivery improvement (Batho Pele handbook, 2003).

Examples of companies and institutions that have adapted Ubuntu applying Batho Pele principles include: the Department of Education, American Express, First National Bank, Pick n Pay and South African Airways (Ngidi \& Dorasamy, 2014). It is argued here that Ubuntu leadership style has the potential to overcome challenges that hinder multi-national team productivity and performance because it enables team members to tolerate each other's cultural differences that might otherwise result in low service delivery performance. We conclude that Ubuntu in management encourages team members to strive to enact the four values leading to a positive impact for EWC. We now propose the following propositions regarding management of the workplace in an Ubuntu culture centred community:

Proposition 1: Employee commitment to co-worker and supervisor which are positively related to Ubuntu collective-values lead to employee collective achievement of service quality performance goals.

Proposition 2: Employee's service quality behaviour and $\mathrm{OC}$ will be mediated by Ubuntu values, when facilitated by a management style that ensures the interest of the community of employees ahead of the interests of any individual.

\section{MATERIAL AND METHODS}

Identifying literature associated with and appropriate for the argument presented in this article entailed a search for published empirical findings. Consistent with Cohen (1992, p. 1142), lists of secondary literature sources were reviewed to source past research. This strategy perused online databases, both global and African, for academic research (1960 to 2017), using Google scholar sourced articles, the South African catalogues of PhD theses, including PSYCINFO, SABINET, EBSCOHOST, Elsevier Science Direct, SAGE, Emerald, and, Taylor \& Francis.

Secondary literature sources identified preliminary studies on $\mathrm{OC}$ and related variables from 1990 to 2002. These were used to identify older seminal sources that referenced Becker (1960) and Mowday et al. (1979). The search applied the search terms: OC, OB, organisational management, cross-culture, Ubuntu. This yielded 300 empirical and conceptual articles which were reviewed to reduce and rationalise the appropriateness of the context as per the 'prescribed criteria' (Zhao, 2016, p. 2437): 
1. Reviewing social citation indices for the most cited studies to identify pertinent explanations of $O C$ and $O B$;

2. Selecting studies and drawing explanations (from selected service business contexts that considered culture in management practice-financial services, the banking sector, and tourism and hospitality) that measured specific variables, namely those addressing cultural values with culture dimension predictors in OC relationships;

3. Considering research on organisational outcomes, such as service delivery quality, that integrate cultural dimension perspectives to construct a unified theoretical basis for understanding the development process of EWC in terms of Ubuntu;

4. Limiting our focus to cross cultural influences and target referents that conceptualised EWC from a person-centred approach (Meyer et al., 2012). Reviewing EWC through the lens of Ubuntu proverbs creating value to an organisation's management by describing a particular set of African values to supplement more wellknown cultural dimension frameworks.

Our review additionally highlights Ubuntu values from a sociolinguistic perspective, illustrated through a selection of African proverbs. Proverbs constitute one of the African mediums through which the virtues of Ubuntu are transferred from one generation to another (Kamwangalu, 1999). We followed Broodryk's (2002) recommendation suggesting the use of proverbs to articulate understanding of a community embracement of social values.

\section{RESULTS AND DISCUSSION}

In this article we address two contemporary research issues: firstly, the scarcity of research in contemporary management espousing an Ubuntu collective sense for management in developing supervisor-employee relationships. Secondly, the growing realisation that cultural dimensions viz.: individualism, collectivism and power distances that exist among employees of different cultures, such as in South Africa, are very important for managers to be aware of in attaining optimal workplace commitment. A simple way to effect the two propositions to encourage Ubuntu style of management is for a manager to demonstrate consistently the four Ubuntu values, by being present physically and emotionally when employees need to be one with their manager (Molose, 2017).

A manager stands to benefit when understanding it because of his/her team making him/her successful. This genuine authenticity/realness of their managers is postulated as improving EWC and OC. Ubuntu style leadership is argued here to help managers facilitate collective decision making by genuinely valuing the worth of each employee. This consequently creates organisational benefits through a shared will to succeed. We argue that adopting Ubuntu collective values provides a unique approach to managing teams, helping explain the importance of collective achievement of organisational goals. The challenge for managers is to take advantage of Ubuntu as a unique approach to be adopted in conjunction with established cultural dimension frameworks.

Theoretically, the collective values framework of Ubuntu has several potential advantages. It takes a multidimensional approach to avoid the cultural limitations of previous models. It also acknowledges that $\mathrm{OC}$ has different meanings to different people. Finally, the framework stresses the importance of Ubuntu motivational forces as mechanisms to 
facilitate EWC, highlighting affective and normative mind-sets as the strongest components of $O C$ in cultures that exhibit collectivist values.

\section{CONCLUSIONS}

We argue that this framework gives insight into the heart of individualism-collectivism and power distance operationalisation, making the principle of Ubuntu cultural group solidarity important to consider in future management research. The framework with related propositions captures the concepts for managers striving to understand employee group cohesion mechanisms like 'we are one' related to optimising OC and OB. Organisational productivity requirements of managers, such as assuring service excellence suggest that EWC is inseparable from the team and its manager. The implications of Ubuntu in the context of extending existing theories of individualism-collectivism and power distance cannot be overstated. Therefore, to contribute to global management knowledge by interpreting Ubuntu, we borrow from an eloquent message by African author Nyathi (2008, p. 13):

'Ubuntu is a well-developed system of knowledge that stands in contrast to the dominant Euro-American epistemology. Articulating this alternative epistemology in the white-western world of organizational studies is an extremely challenging task (in the ways it raises 'lost in translation' type issues), but for an African person this challenge is not entirely new. It is an extension of struggles to articulate the identity of Africa and the Africans dating back to the late eighteenth century'.

\section{REFERENCES}

Astakhova, M.N. (2016). Explaining the effects of perceived person-supervisor fit and person-organization fit on organisational commitment in the U.S. and Japan. Journal of Business Research, 69(2), 956-963. https://doi.org/10.1016/j.jbusres.2015.08.039

Batho Pele Handbook. (2003). A service delivery improvement guide. Department of Public Service and Administration. Pretoria: GCIS.

Battle, M. (1996). The ubuntu theology of Desmond Tutu. In L. Hulley, L. Kretzchmar \& L.L. Pato (Eds.), Archbishop Tutu: Prophetic witness in South Africa. Cape Town: Human \& Rousseau (pp. 93-105).

Becker, H.S. (1960). Notes on the concept of commitment. American Journal of Sociology, 66, 32-42.

Broodryk, J. (2002). Ubuntu: Life lessons from Africa, Ubuntu School of Philosophy, Pretoria. South Africa.

Brotherton, B., \& Wood, R.C. (2008). The nature and meaning of hospitality: The sage handbook of hospitality management. London: British library.

Browning, V. (2006). The relationship between HRM practices and service behaviour in South African service organizations. International Journal of Human Resource Management, 17(7), 13211338. https://doi.org/10.1080/09585190600756863

Christie, P., Lessem, R., \& Mbigi, L. (1993). African Management: Philosophies, Concepts and Applications. Johannesburg: Knowledge Resources.

Cohen, A. (1993). Organizational commitment and turnover: A meta-analysis. Academy of Management Journal, 36(5), 1140-1157.

Dhar, R.L. (2015). Service quality and the training of employees: The mediating role of organizational commitment. Tourism Management 46, 419-430. https://doi.org/10.1016/j.tourman.2014.08.001 
Fischer, R., \& Mansell, A. (2009). Commitment across culture: A Meta analytical approach. Journal of International Business Studies, 40, 1339-1358. https://doi.org/10.1057/jibs.2009.14

Gellatly, I.R., Meyer, J.P., \& Luchak, A.A. (2006). Combined effects of the three commitment components on focal and discretionary behaviors: A test of Meyer and Herscovitch's propositions. Journal of Vocational Behavior, 69, 331-345. https://doi.org/10.1016/j.jvb.2005.12.005

Hofstede, G. (1980). Culture's consequences: International differences in work-related values. London and California: Sage Publication.

Honeycutt, J.M. (1989). A functional analysis of imagined interaction activity in everyday life. In J.E. Shorr, P. Robin, J.A. Connella \& M. Wolpin (Eds.), Imagery (pp. 13-25). Boston. MA: Springer.

House, R.J., Hanges, P.J., Javidan, M., Dorfman, P.W., \& Gupta, V. (2004). Culture, leadership and organisations: The Globe study of 62 societies, $1^{\text {st }}$ ed. Thousand Oaks, London: Sage Publications.

Hrebiniak, L.G, \& Alutto, J.A. (1972). Personal and role-related factors in the development of organizational commitment. Administrative Science Quarterly, 17, 555-573.

Jackson, T. (2004). Management and change in Africa: A cross-cultural perspective. London: Routledge.

Jaiswal, D., \& Dhar, R.L. (2016). Impact of perceived organizational support, psychological empowerment and leader member exchange on commitment and its subsequent impact on service quality. International Journal of Productivity and Performance Management, 65(1), 58-79. https://doi.org/10.1108/IJPPM-03-2014-0043

Kamwangalu, N. (1999). Ubuntu in South Africa: A sociolinguistic perspective to a Pan African concept. Critical Arts, 13(2), 24-41.

Khoza, R.J. (2005). Let Africa lead. Sunninghill: Vezubuntu.

LaMastro, V. (1999). Commitment and perceived organisational support. National Forum of Applied Educational Research Journal, 12(3), 1-13.

Li., J.J., Kim, W.G., \& Zhao, X.R. (2017). Multilevel model of management support and casino employee turnover intention. Tourism Management, 59, 193-204. https://doi.org/10.1016/j.tourman.2016.08.006

Limpanitgul, T., Boonchoo, P., Kulviseachana, S., \& Photiyarach, S. (2017). The relationship between empowerment and the three-component model of organisational commitment: an empirical study of Thai employees working in Thai and American airlines. International Journal of Culture, Tourism and Hospitality Research, 11(2), 227-242. https://doi.org/10.1108/IJCTHR-07-2015-0069

Lutz, D.W. (2009). African Ubuntu Philosophy and Philosophy of Global

Management. Journal of Business Ethics, 84 (3), 313-328. https://doi.org/10.1007/s10551-009-0204-z

MacDonald, P., Kelly, S., \& Christen, S. (2014). A Path Model of Workplace

Solidarity, Satisfaction, Burnout, and Motivation. International Journal of Business Communication, 1-19. https://doi.org/10.1177/2329488414525467

Mangaliso, M.P. (2001). 'Building a competitive advantage from ubuntu: Management lessons from South Africa'. The Academy of Management Executive, 15(3), 23-33.

Mastrangelo, A., Eddy, E.R., \& Lorenzet, S.J. (2004).The importance of personal and professional leadership. The Leadership \& Organization Development Journal, 25(5), 435-451.

Mathieu, J.E., \& Zajac, D.M. (1990). A Review and Meta-Analysis of the antecedents, correlates, and consequences of organizational commitment. Psychological Bulletin, 108(2), 171-194.

Mbigi, L., \& Maree, J. (1995). The spirit of African transformation management. Pretoria: Sigma.

Mbigi, L. (1997). Ubuntu: The African dream in management. Pretoria: Knowledge Resources. 
Meyer, J.P., \& Allen, N.J. (1991). A three component conceptualisation of organizational commitment. Human Resources Management Review, 1(1), 61-89.

Meyer, J.P., Stanley, D.J., Herscovitch, L., \& Topolnytsky, L. (2002). Affective, continuance, and normative commitment to the organization: A meta-analysis of antecedents, correlates, and consequences. Journal of Vocational Behavior, (61), 20-52. https://doi.org/10.1006/jvbe.2001.1842

Meyer, J.P., \& Maltin, E.R. (2010). Employee commitment and well-being: A critical review, theoretical framework and research agenda. Journal of Vocational Behavior, 77, 323-337.

Meyer, J.P., Stanley, D.J, Jackson, T.A, Mclnnis, K.J. Maltin, E.R., \& Sheppard, L. (2012). Affective, normative, and continuance commitment levels across cultures: A meta-analysis. Journal of $V_{o}$ cational Behavior, 80, 225-245. https://doi.org/10.1016/j.jvb.2011.09.005

Meyer, J.P., Morin, A.J.S., \& Vandenberghe, C. (2015). Dual commitment to organization and supervisor: A person-centered approach. Journal of Vocational Behavior, (88), 56-72. https://doi.org/10.1016/j.jvb.2015.02.001

Metz, T. (2007). Towards an African moral theory. Journal of Political Philosophy, 15(3), 321-341.

Modise, T. (2006, May 24). Mandela, N.R. Interviewed by Tim Modise. Experience Ubuntu Interview. Retrieved on June 30, 2017 from Wikipedia: http://en.wikipedia.org/wiki/file:Experience

Molose, T. (2017). Organisational commitment in the hospitality sector. Unpublished doctoral dissertation, University of Johannesburg, South Africa.

Mowday, R.T., Steers, R.M., \& Porter, L.W. (1979). The measurement of organizational commitment. Journal of Vocational Behavior, 14, 224-247.

Msengana, N.W. (2006). The significance of the concept of Ubuntu for educational management and leadership during democratic transformation in South Africa. Unpublished doctoral dissertation, University of Stellenbosch, South Africa.

Ndaba, W.J. (1994). Ubuntu in comparison to western philosophies. Pretoria: Ubuntu School of Philosophy.

Ngidi, T.L., \& Dorasamy, N. (2014). Imperatives for Good Government: A case study of the implementation Batho Pele principles at Durban Home Affairs Regional level. Journal of Social Sciences, 38(1), 9-21.

Nicolaides, A. (2010, August). Cultural diversity training programme development for hospitality and tourism industry enterprises. Paper presented at an International Research Symposium in Service Management, Mauritius.

Nussbaum. B. (2003). Ubuntu: Reflections of a South African on our Common Humanity. Reflections, 4(4), 21-26.

Nyathi, N. (2008). The organisational imagination in African anti-colonial thought. Unpublished doctoral dissertation, University of Leicester, United Kingdom.

Poovan, N., Du Toit, M.K., \& Engelbrecht, A.S. (2006). The effect of the social values of Ubuntu on team effectiveness. South African Journal of Business Management, 37(3), 17-27.

Ritzer, G., \& Trice, H. (1969). Empirical study of Howard Becker's side-bet theory. Social Forces, (47), 475-479.

Rousseau, D.M. (1989). Psychological and implied contracts in Organizations. Employee Responsibility and Rights Journal, 2(2), 121-139.

Srivastava, A.P., \& Dhar, R.L. (2016). Impact of leader member exchange, human resource management practices and psychological empowerment on extra role performances: The mediating role of organisational commitment. International Journal of Productivity and Performance Management, 65(3), 351-377. 
Stebbins, R.A. (1970). On misunderstanding the concept of organisational commitment: A theoretical clarification. Social Forces, 48, 526-529.

Steers, R.M. (1977). Antecedents and outcomes of organizational commitment. Administrative Science Quarterly, 22(1), 46-56.

Stinglhamber, F., \& Vandenberghe, C. (2003). Organization and supervisors as sources of support and targets of commitment: a longitudinal study. Journal of Organisational Behaviour, 24(3), 251-270.

Tett, R.P., \& Meyer, J.P. (1993). Job satisfaction, organizational Commitment, turnover intention, and Turnover: path analyses based on Meta analytic findings. Personal Psychology, 46, 259-293.

Tutu, M.P. (1995). 'The Right to Hope'. Thick, C. (Ed.) Global Problems, Global Vision. UK: Earthscan Publications.

Tutu. D. (2004). God has a Dream: A Vision of Hope for our Time: New York Doubleday.

Valickas, A., Raišienè, A. G., \& Arimavičiūtè, M. (2017). Leadership competences for the excellence of municipalities' strategic management. Journal of International Studies, 10(4), 131-142. doi:10.14254/2071-8330.2017/10-4/10

Vveinhardt, J., Andriukaitiene, R. (2017). Management Culture as Part of Organizational Culture in the Context of Corporate Social Responsibility Implementation. Economics and Sociology, 10(3), 294-320. doi:10.14254/2071-789X.2017/10-3/21

Westmoreland, M.W. (2008). Interruptions: Derrida and Hospitality. Kritike, 2(1), 1-10.

Wiener, Y. 1982. Commitment in Organizations: A normative view. Academy of Management Review, 7(3), 418-428.

Woermann, M., \& Engelbrecht, S. (2017). The Ubuntu Challenge to Business: From Stakeholders to Relationholders. Journal of Business Ethics. https://doi.org/10.1007/s10551-017-3680-6

Yukl, G. (2002). Leadership in organisations. Englewood: Prentice-Hall.

Zhao, X.R. (2016). Work-family studies in the tourism and hospitality contexts. International Journal of Contemporary Hospitality Management, 28(11), 2422-2445. 


\section{Authors}

The contribution share of authors is equal and amounted to $50 \%$ each of them.

\section{Thembisile Molose}

Completed this research as a PhD candidate, College of Business and Economics, University of Johannesburg. His research interests include service innovation performance, organisational behaviour and strategic management.

Correspondence to: Thembisile Molose, Department of Business Management, P.O. Box 524, APK, University of Johannesburg, 2006, South Africa, e-mail: moloset@cput.ac.za

\section{Geoff Goldman}

Associate Professor, Head of the Department of Business Management, College of Business and Economics, University of Johannesburg. Professor Goldman's research interests including Critical Management Studies, Business Ethics and Strategy Implementation. He is the managing editor of the South African management journal Acta Commercii, and serves on the editorial panel of journals in the UK and Poland, and on the international advisory boards of the Milpark Business School, South Africa, and the Krakow School of Business in Poland.

Correspondence to: Prof. Geoff Goldman, Department of Business Management, P.O. Box 524, APK, University of Johannesburg, 2006, South Africa, e-mail: ggoldman@uj.ac.za

\section{Peta Thomas}

Senior lecturer, College of Business and Economics, University of Johannesburg. Dr. Thomas' research interests are African business management and South African national parks.

Correspondence to: Dr. Peta Thomas, Department of Business Management, P.O. Box 524, APK, University of Johannesburg, 2006, South Africa, e-mail: pthomas@uj.ac.za

\section{Acknowledgements and Financial Disclosure}

The authors declare that no financial support was received for this research.

\section{Copyright and License}

This article is published under the terms of the Creative Commons Attribution - NoDerivs (CC BY-ND 4.0) License http://creativecommons.org/licenses/by-nd/4.0/

Published by the Centre for Strategic and International Entrepreneurship - Krakow, Poland 